\title{
Correction to: The Gender Similarities Hypothesis: Insights From A Multilevel Analysis of High-Stakes Examination Results in Mathematics
}

\author{
Ian Cantley ${ }^{1} \cdot$ James McAllister $^{1}$
}

Published online: 16 August 2021

๑) Springer Science+Business Media, LLC, part of Springer Nature 2021

\section{Correction to: Sex Roles \\ https://doi.org/10.1007/s11199-021-01234-5}

In the version of this article originally published, several words that are needed for adequate interpretation of the text in the second sentence of the third paragraph under the Limitations and Future Directions section are missing.

Specifically, the sentence should read as follows: However, there is scope to classify the various items on the assessment units into cognitive domains (e.g., knowledge, application, reasoning, problem-solving) rather than content domains, to facilitate an analysis of gender differentials in cognitive domain-specific achievement.

The original article has been corrected.

Ian Cantley

i.cantley@qub.ac.uk

James McAllister

jmcallister22@qub.ac.uk

1 School of Social Sciences, Education and Social Work, Queen's University Belfast, 69-71 University Street, Belfast BT7 1HL, UK 